\title{
Biomechanics of Running Indicates Endothermy in Bipedal Dinosaurs
}

\author{
Herman Pontzer ${ }^{1 *}$, Vivian Allen ${ }^{2}$, John R. Hutchinson ${ }^{2}$
}

1 Department of Anthropology, Washington University, St. Louis, Missouri, United States of America, 2 Structure and Motion Laboratory, Department of Veterinary Basic Sciences, The Royal Veterinary College, London, United Kingdom

\begin{abstract}
Background: One of the great unresolved controversies in paleobiology is whether extinct dinosaurs were endothermic, ectothermic, or some combination thereof, and when endothermy first evolved in the lineage leading to birds. Although it is well established that high, sustained growth rates and, presumably, high activity levels are ancestral for dinosaurs and pterosaurs (clade Ornithodira), other independent lines of evidence for high metabolic rates, locomotor costs, or endothermy are needed. For example, some studies have suggested that, because large dinosaurs may have been homeothermic due to their size alone and could have had heat loss problems, ectothermy would be a more plausible metabolic strategy for such animals.

Methodology/Principal Findings: Here we describe two new biomechanical approaches for reconstructing the metabolic rate of 14 extinct bipedal dinosauriforms during walking and running. These methods, well validated for extant animals, indicate that during walking and slow running the metabolic rate of at least the larger extinct dinosaurs exceeded the maximum aerobic capabilities of modern ectotherms, falling instead within the range of modern birds and mammals. Estimated metabolic rates for smaller dinosaurs are more ambiguous, but generally approach or exceed the ectotherm boundary.

Conclusions/Significance: Our results support the hypothesis that endothermy was widespread in at least larger non-avian dinosaurs. It was plausibly ancestral for all dinosauriforms (perhaps Ornithodira), but this is perhaps more strongly indicated by high growth rates than by locomotor costs. The polarity of the evolution of endothermy indicates that rapid growth, insulation, erect postures, and perhaps aerobic power predated advanced "avian" lung structure and high locomotor costs.
\end{abstract}

Citation: Pontzer H, Allen V, Hutchinson JR (2009) Biomechanics of Running Indicates Endothermy in Bipedal Dinosaurs. PLoS ONE 4(11): e7783. doi:10.1371/ journal.pone.0007783

Editor: Andrew Allen Farke, Raymond M. Alf Museum of Paleontology, United States of America

Received August 12, 2009; Accepted October 14, 2009; Published November 11, 2009

Copyright: (c) 2009 Pontzer et al. This is an open-access article distributed under the terms of the Creative Commons Attribution License, which permits unrestricted use, distribution, and reproduction in any medium, provided the original author and source are credited.

Funding: Washington University, USA supported HP for this project. The National Science Foundation, USA funded JRH from 2001-2003, which supported development of this work, as did the Department of Veterinary Basic Sciences at The Royal Veterinary College (2003-2009). The funders had no role in study design, data collection and analysis, decision to publish, or preparation of the manuscript.

Competing Interests: The authors have declared that no competing interests exist.

*E-mail: hpontzer@artsci.wustl.edu

\section{Introduction}

The metabolic physiology of dinosaurs and their extinct relatives whether they were ectothermic ("cold blooded") like modern reptiles, or endothermic ("warm blooded") like birds and mammals - is important for reconstructing their ecology, behavior, and fate [1-6]. Endothermic animals are better able to inhabit a wide range of climates and maintain higher levels of activity than ectotherms, and thus much of our understanding of dinosaur paleoecology and evolution hinges on this critical distinction. Evidence for competing views of dinosaur metabolic physiology has come from a range of sources, including the anatomy of ventilatory organs [7-9], the apparent absence of ossified respiratory turbinates [10], reconstructed posture, habitat, and ecology [2,3,11-13], analogies with extant taxa based on experimental studies [13], the presence of feathers or filamentous integument $[14,15]$, and especially bone histology and growth [16-20], with much recent work suggesting at least some degree of endothermy.

High growth rates and perhaps activity levels seem to have been ancestrally present in the clade Ornithodira (dinosaurs, pterosaurs, and all descendants of their most recent common ancestor) $[21,22]$, in addition to perhaps some form of potentially-insulative filamentous integument [15]. Thus these characteristics apparently predate the parallel evolution, in pterosaurs and saurischians, of advanced respiratory systems (e.g., expanded air sacs and one-way air flow; [7-9]). Many studies take these features to indicate high metabolic rates and thus endothermy (or at least intermediate stages in its evolution) in extinct dinosaurs and other ornithodirans [6]. The question remains whether endothermy evolved earlier in Ornithodira, or independently in Pterosauria and Saurischia [e.g., 19]. Some researchers remain unconvinced of endothermy even in non-ornithurine birds (e.g. [10,16]) or tentatively favor more complex scenarios involving multiple origins of endothermy [12]. Independent evidence would help distinguish between these alternative hypotheses.

In modern mammals and birds, endothermy incurs an energy cost of maintaining a high basal metabolic rate, but provides a substantial advantage in aerobic capacity over ectothermic reptiles. Whereas endotherms and ectotherms are capable of similar peak power output during short bursts, the maximum 
aerobically sustained metabolic rate, also termed "maximum aerobic power" or $\mathrm{VO}_{2} \mathrm{max}$, is an order of magnitude greater for endotherms [23]. Consequently, sustained locomotor activity, which incurs similar costs for both groups [24], is relatively infrequent and limited to moderate running speeds in extant ectotherms $[1,25]$. While increased locomotor activity might not have provided the initial evolutionary advantage for endothermy $[26,27]$, sustained aerobic activity provides a clear distinction between modern endothermic and ectothermic vertebrates; the metabolic physiology of modern ectothermic reptiles cannot sustain the aerobic activity commonly seen in birds and mammals.

To assess the metabolic physiology of extinct dinosaurs and thereby test whether individual taxa fit endothermic or ectothermic models better, we compared estimated metabolic rates (oxygen consumption; $\mathrm{mlO}_{2} \mathrm{~s}^{-1}$ ) during walking and running in thirteen bipedal dinosaurs and one dinosauriform outgroup, Marasuchus ("Lagosuchus"; Sereno and Arcucci, 1994) to maximum aerobic power, $\mathrm{VO}_{2} \max \left(\mathrm{mlO}_{2} \mathrm{~s}^{-1}\right)$, for living endotherms and ectotherms. We used two recently developed methods linking locomotor anatomy to walking and running cost to estimate locomotor metabolic rates for dinosaurs (Fig. 1). Since walking and slow to moderate-speed running are aerobically sustainable in most modern amniotes $[1,25,28]$, ectothermy in extinct species would be supported if their predicted locomotor costs at these moderate speeds fall within the aerobic capacity seen in living ectotherms. Alternatively, if the aerobic power needed for walking and slow running in these extinct species is predicted to exceed the maximum aerobic power for ectotherms, this would suggest these species were endothermic. We focused on bipedal species, because issues of weight distribution between fore- and hind limbs make biomechanical analysis of extinct quadrupeds more difficult and speculative.

\section{Results}

Surprisingly, the estimated locomotor metabolic rates for many dinosauriforms, especially larger taxa in our sample, consistently exceeded the $95 \%$ confidence interval for maximum aerobic power, $\mathrm{VO}_{2}$ max, seen in extant ectotherms (Figure 2). Locomotor power requirements $\left(\mathrm{mlO}_{2} \mathrm{~s}^{-1}\right)$ estimated from hip height exceeded ectothermic capabilities at moderate running speeds (Fr 1.0) for all species, and at a slow run (Fr 0.50) for all but the smallest species (Archaeopteryx). Even during walking (Fr 0.25), the required metabolic output for the five largest species (a juvenile Gorgosaurus, Dilophosaurus, Plateosaurus, Allosaurus, and Tyrannosaurus) exceeded the range of aerobic capacity seen in extant ectotherms
(Figure 2). Similarly, locomotor cost estimates based on active muscle volume, $V_{\text {musc }}$, exceeded ectothermic capabilities at all walking and running speeds for the five largest species, and at moderate running speeds in the small, presumably active bipeds, Heterodontosaurus, Compsognathus and Velociraptor. Only the smallest species, Archaeopteryx, had estimated locomotor metabolic rates that fell within or near the range of $\mathrm{VO}_{2} \max$ seen in modern ectotherms, for all but the fastest speeds using both hip height and $\mathrm{V}_{\text {musc }}$ approaches (Figure 2; Table 1).

Differences between hip height- and $\mathrm{V}_{\text {musc }}$-based estimates of dinosauriform locomotor cost highlight the different assumptions underlying each method. The reconstructed posture used to estimate $\mathrm{V}_{\text {musc }}$ employs more extended joints than expected for the smallest animals in our analysis [29]. More crouched poses, like those of similarly-sized extant species [29], would result in lower effective mechanical advantage (EMA) for the muscles, and hence produce higher estimates of locomotor cost [30]. This suggests that hip-height based estimates, which assume that EMA values for small dinosauriforms are similar to similarly-sized modern vertebrates, are likely more accurate for the small species in our dataset. Notably, hip height-based estimates consistently placed slow and moderate running costs for the smaller dinosauriforms within the endothermic range of aerobic output (Table 1, Figure 2). Conversely, the hip height approach assumes extremely extended limb postures for the largest dinosaurs, like those of walking elephants and other similarly-sized extant vertebrates. Such extended, "columnar" limb postures are incommensurate with the joint morphology and probable limb configuration of these species [5,31], suggesting that the $V_{\text {musc }}$ approach, which provides higher estimates of cost, is likely more accurate for the largest dinosaurs in our sample.

Phylogenetic analysis of our data supports the hypothesis that an endothermic level of metabolism was needed to power at least slow running gaits in all Dinosauriformes (Figure 3). If a conservative approach is taken, using only locomotor cost estimates for slow walking, for which our two methods identify the same set of taxa as endothermic, then the hypothesis that endothermy arose independently at least three times (in Sauropodomorpha, Tetanurae and Neornithes) and was lost once (in Coelurosauria) is favored. This is at odds with insulatory and histological evidence for endothermy at least in coelurosaurs $(14,15,18,19,20,22)$, but would correspond to some degree of coevolution of advanced ventilator structure, large body size and endothermy. An alternative, less conservative approach, using locomotor cost estimates for moderate speed running from our simple hip height-based

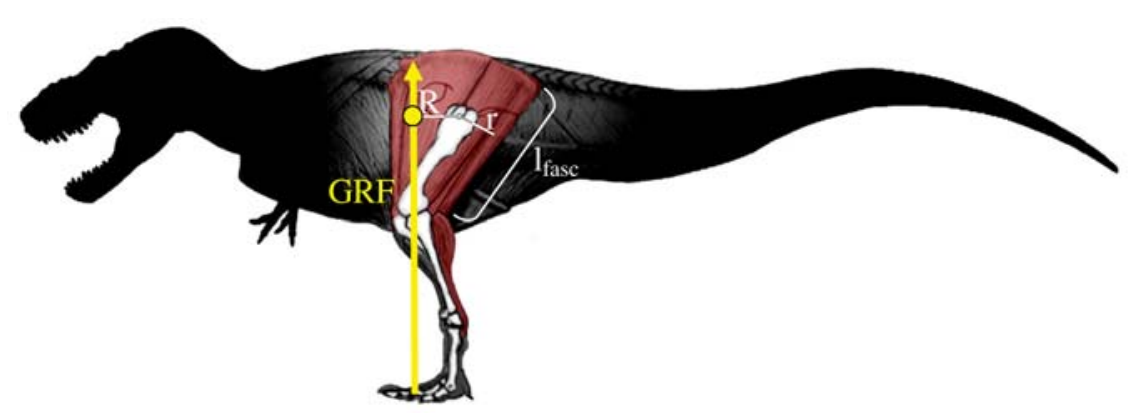

Figure 1. Schematic of extensor fascicle length $\left(I_{\text {fasc }}\right)$, the GRF vector moment arm ( $R$; segmental gravitational, but not inertial, moments were also included but not shown here; see [48]), and the extensor (antigravity) muscle moment arm (r) for the hip joint. These parameters were calculated at midstance for the antigravity muscle groups at the hip, knee, and ankle, and combined with step length (estimated from hip height) to estimate the volume of muscle activated per meter travelled ( $\left.\mathrm{V}_{\text {musc }}\right)$; see Methods. Joint angles and position of the center of mass (yellow circle) are taken from Hutchinson [40]. Adapted with permission from original artwork by Scott Hartman.

doi:10.1371/journal.pone.0007783.g001 

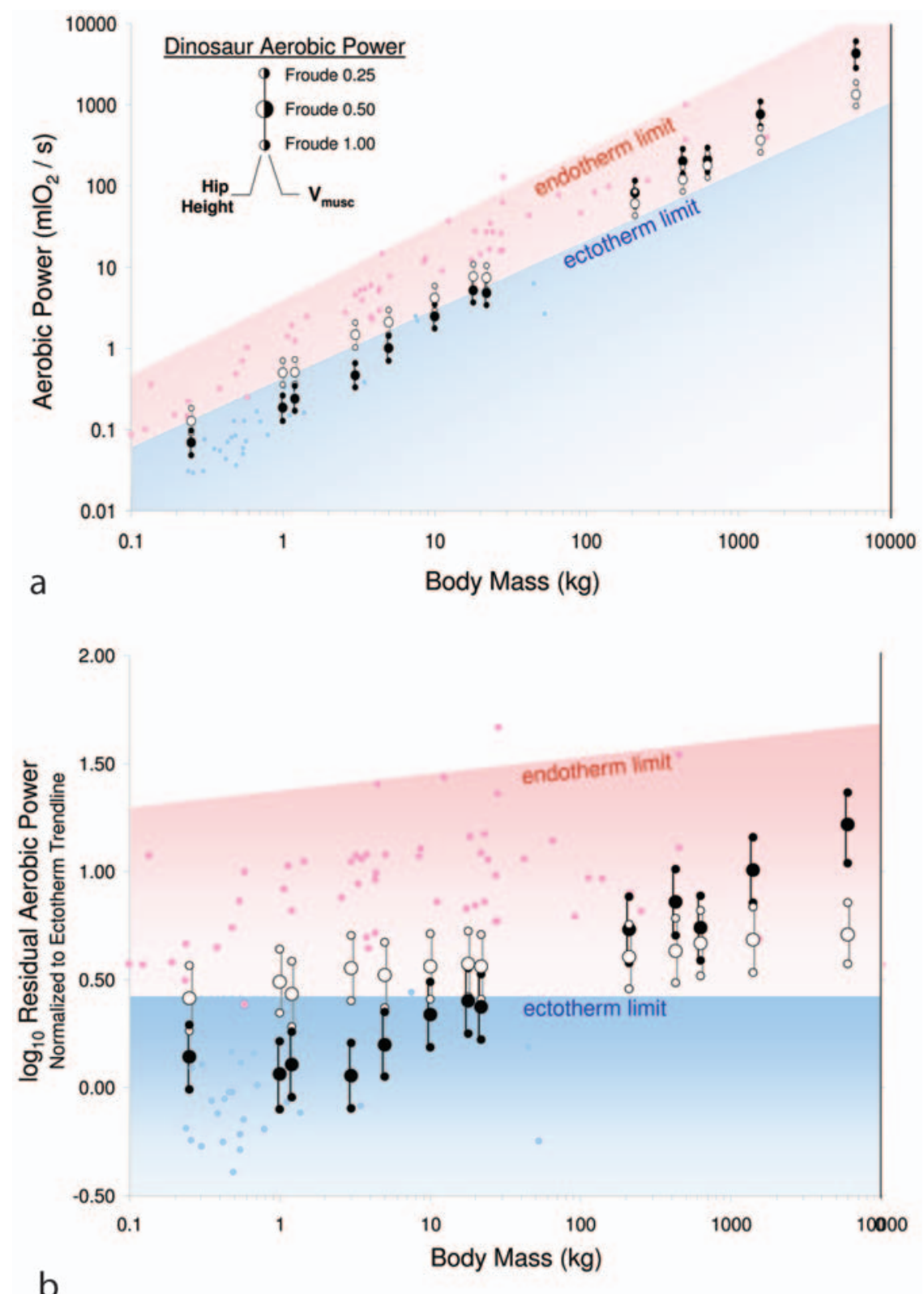

Figure 2. A. Locomotor power requirements for dinosauriforms (aeroic power, $\mathrm{mlO}_{2} / \mathrm{s}$ ) plotted on a graph of maximum aerobic power $\left(\mathrm{VO} \mathrm{O}_{2 \mathrm{max}}\right.$ $\mathrm{mlO} 2 / \mathrm{s})$, for extant endotherms (light red circles and shaded region) and ectotherms (blue circles and shaded region) versus body mass. Estimated rates of oxygen consumption for dinosauriforms are calculated using the two methods described in the text for walking (Froude 0.25 ), slow running (Froude 0.50), and moderate running (Froude 1.00) speeds (from left to right, Archaeopteryx, Marasuchus, Microraptor, Compsognathus, Lesothosaurus, Heterodontosaurus, Coelophysis, Velociraptor, Gorgosaurus, Dilophosaurus, Plateosaurus, Allosaurus, Tyrannosaurus). White symbols are estimates from hip height, black symbols are estimates from active muscle volume, $\mathrm{V}_{\text {musc. }}$. The data points for Coelophysis and Velociraptor (both $20 \mathrm{~kg}$ ) have been separated slightly for clarity. The upper limit of maximum aerobic power for modern ectotherms (i.e., the upper $95 \%$ confidence limit) is indicated by the upper boundary of the blue region; the upper limit for modern endotherms is indicated by the upper boundary of the red region. B. A similar plot as in A showing $\log _{10}$ residuals from the ectotherm trendline.

doi:10.1371/journal.pone.0007783.g002

method, supports the hypothesis that endothermic physiology and aerobic power were ancestral for dinosauriforms.

\section{Discussion}

These results strongly suggest endothermy for larger $(>20 \mathrm{~kg})$ bipedal dinosaurs, because other explanations require physiological adaptations or locomotor limitations unseen in living terrestrial vertebrates. For example, it might be proposed that extinct dinosauriforms were ectothermic, but were able to achieve a greater $\mathrm{VO}_{2}$ max than modern reptiles. While the respiratory physiology of dinosaurs has been the subject of much debate [1$8,17,19]$, the latter proposal would require an aerobic scope $\left(\mathrm{VO}_{2} \mathrm{max} /\right.$ Resting Metabolic Rate) for the five largest species in our sample of 30-90x resting rate, far exceeding the maximum aerobic scope in our sample of modern ectotherms (14.5) and even greater than the aerobic scope of most mammals (mean 12.9 \pm 11.0 S.D.; $\max 61.9$; see Table S2). Alternatively, it is possible that 


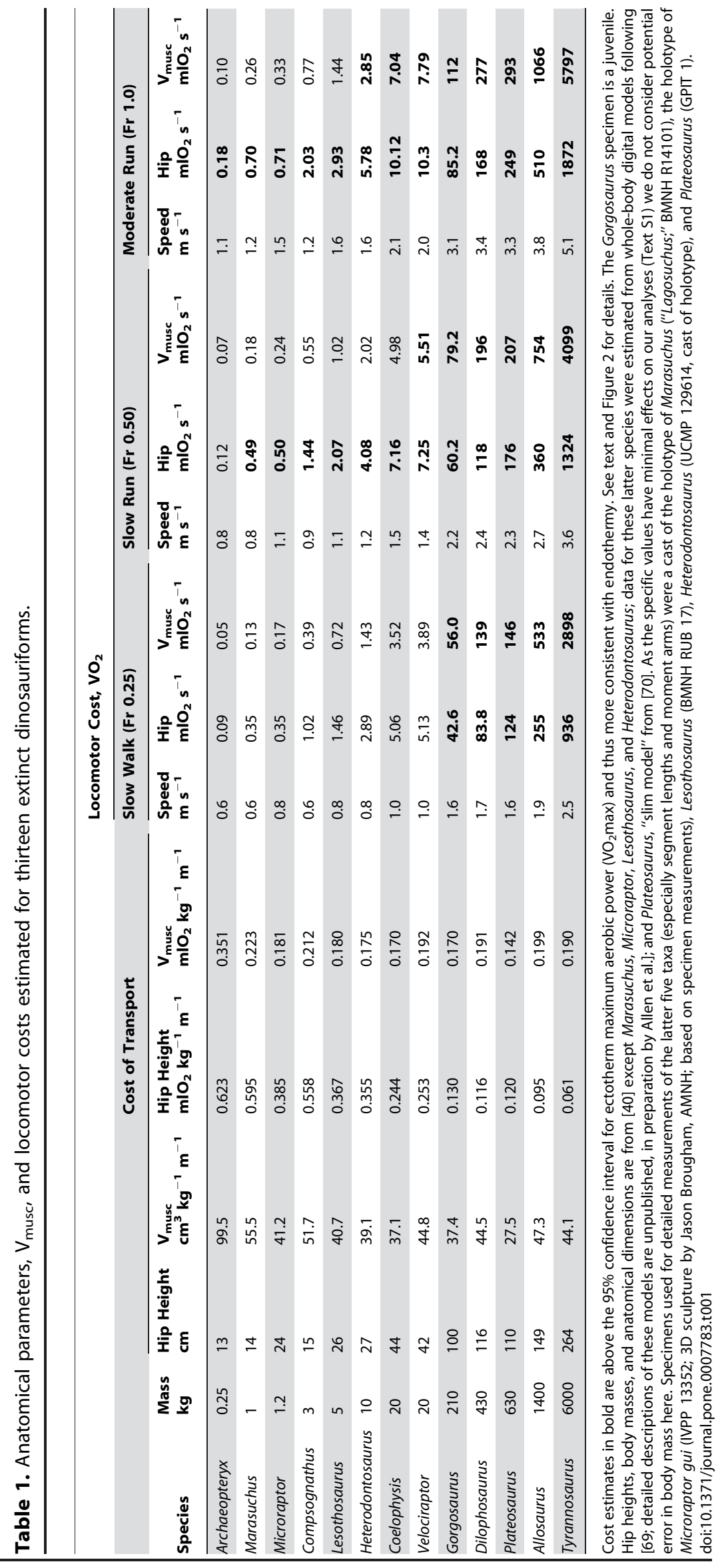



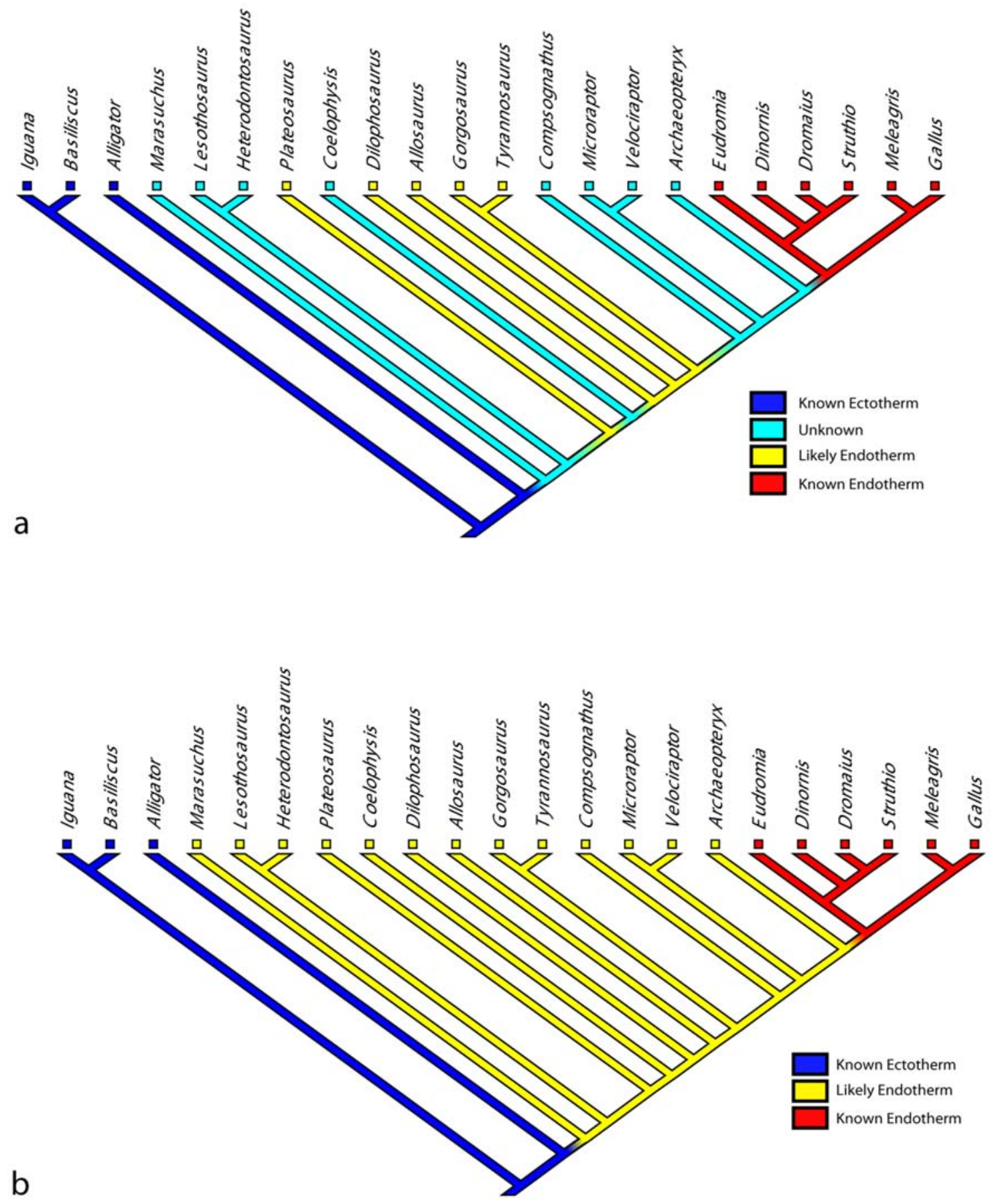

Figure 3. Evolution of locomotor cost and endothermy in Archosauria. A. Estimates from our $\mathrm{V}_{\text {musc }}$-based method for slow walking (Fr 0.25$)$ used to reconstruct the evolution of endothermy. Substantial size-related homoplasy is shown. B. Estimates from our hip height-based method for moderate running ( $\mathrm{Fr} 1.0)$ as a less conservative alternative to Fig. 2A. Endothermy is estimated as ancestral for at least Dinosauriformes. doi:10.1371/journal.pone.0007783.g003

extinct dinosaurs/dinosauriforms did not engage in sustained locomotion, and instead used anaerobic metabolism to fuel short locomotor bouts. However, while intermittent locomotion is often used by modern lizards [32], this would suggest severely limited locomotor performance relative to living reptiles because even walking would need to be fueled anaerobically (Figure 2). Given the high post-exercise metabolic costs incurred by intermittent locomotion [32], utilizing an ectothermic "run now, pay later" strategy with such a high cost of transport would require problematically long, inactive recovery periods, particularly in the largest species. Finally, it could be argued that, by extrapolating the modern ectotherm aerobic power limit to the body size of large theropods, our approach underestimates the aerobic limits for large reptiles. However, while caution must always be used when extrapolating beyond the size range of comparative data, we see no evidence that relationship between aerobic capacity and mass changes at large body sizes among ectotherms or among endotherms. 
Our results for smaller taxa are more ambiguous. The smallest species in our sample are estimated to exceed ectotherm aerobic capacities only at moderate running speeds $(\mathrm{Fr}=1.0)$ and then only marginally (Figure 2). Thus, it is possible that these species were ectotherms that did not engage in sustained moderate or fast running. However, given the active lifestyles suggested for these species in other analyses $[6,33,34]$ it is quite plausible that our conservative approach did not examine costs for sufficiently high speeds. This underscores an important limitation of our analysis. Because both endotherms and ectotherms are capable of producing low levels of aerobic power (i.e., below the upper power limit for ectotherms), species that require low aerobic power to fuel walking and moderate running speeds could be either endothermic or ectothermic. If the aerobic demands at these speeds can be met with either endothermic or ectothermic physiology, our approach cannot distinguish which physiology is more likely. Thus, while species that exceed ectothermic capabilities during slow and moderate locomotion may be reliably classed as endothermic, species that do not exceed ectothermic capabilities at these low and moderate speeds cannot be classed exclusively as ectotherms.

Further work on habitual speeds for the smaller species in our dataset would enable us to adjust the range of speeds modeled to better reflect those commonly used, and would improve the utility of this approach for those species. The limb poses of small dinosauromorphs also warrant further investigation. If the relatively extended postures input for our $\mathrm{V}_{\text {musc }}$-based estimates of cost are correct, this may indicate that relatively upright postures were a strategy that enabled small ectothermic dinosaurs to sustain moderate running speeds.

Large dinosaurs have sometimes been argued to be the most likely to have been ectothermic, based on "inertial homeothermy," heat loss problems, and other constraints including ecological/ energetic ones $[3,13,35,36]$. Our study provides independent results that support the reconstruction of endothermy in large dinosaurs; indeed our method most clearly supports this inference for larger taxa. Likewise, as growth rates and other factors plausibly correlated with endothermy are reconstructed as having relatively different patterns and constraints in smaller- and largerbodied taxa (e.g. [12,19,20,35,37], methods must quantitatively test for size-dependent influences on such factors. Our method does account for size effects, using a hip-height-based approach for smaller taxa and a muscle volume-based approach for larger taxa.

Sensitivity analyses (Text Sl) indicate that our estimates of dinosaur locomotor cost are robust, especially for larger taxa. For example, for Tyrannosaurus, increasing hip height to reflect maximum joint extension only decreases hip height-based estimates of cost by $1.3 \%$ (Text $\mathrm{S} 1$ ). $\mathrm{V}_{\text {musc }}$-based estimates are similarly robust, with the high rates of muscle activation, and hence locomotor cost that are expected for the range of plausible musculoskeletal anatomy and poses in these species. Even for slow running $(\mathrm{Fr}=0.5)$, estimated aerobic power in the large dinosaurs is 3 to 15 standard errors above the ectotherm $\mathrm{VO}_{2} \max$ trendline, or $100-500 \%$ above the upper bound for ectotherm aerobic power. In contrast, two-fold changes of the key unknown parameters (especially estimated body mass, moment arms, or $1_{\text {fasc }}$ ), or moving the center of mass posteriorly to be coincident with the hip joint, result in a maximal total reduction of only $65 \%$ in estimated locomotor cost, still well above the ectotherm range for aerobic capacity (Text S1). Further, the $\mathrm{V}_{\text {musc }}$ approach works for species with known aerobic capacities: it correctly places the extinct moa (Dinornis) and moderate running speeds (Fr 0.5) for extant birds (Gallus and Eudromia) in the endotherm range, and walking and slow running in Iguana, Basiliscus, and Alligator in the ectotherm range for $\mathrm{VO}_{2} \max$ (Figure $\mathrm{S} 1$ ).
Our findings concur with multiple lines of independent evidence from bone histology [18,19,22] and cardiorespiratory anatomy $[7,8]$ indicating high growth rates and activity levels, if not endothermy, in Dinosauriformes. As locomotor costs were somewhat high for all dinosauriforms, this is consistent with the hypothesis that endothermy was ancestral for the entire clade. As pterosaurian outgroups had advanced bone histology [19,21] and respiratory anatomy [38] as well as long muscular hindlimbs similar to those of dinosauriforms (although bipedalism/quadrupedalism remains controversial), the most parsimonious hypothesis is that endothermy first evolved in the shared common ancestor of Pterosauromorpha and Dinosauromorpha, in the clade Ornithodira. Since pterosaur anatomy, posture and gait remain highly controversial, and basal pterosauromorph taxa are quite small in body size, we considered it too speculative and ultimately ambiguous to apply our methods to pterosauromorphs, but predict that if such models could justifiably be done, our results would be further strengthened. Likewise, our analysis does not include quadrupedal dinosaurs, and therefore excludes many of the largest dinosaurs, such as sauropods. Analyses of the postures and weight distribution for these large quadrupeds are needed to test whether the high aerobic power requirements for bipedal forms seen here were common among large dinosauromorphs.

Our methodology adds a new, repeatable line of evidence that is explicitly and quantitatively linked with well-demonstrated metabolic mechanisms that underlie fundamental differences between endothermic and ectothermic species, and its assumptions are checked with sensitivity analysis. Our results provide new support, in agreement with other strong lines of evidence $[2,3,11,14,18-20]$, that endothermy was present in many, if not all, non-avian dinosaurs, especially larger taxa. Endothermy still plausibly was plesiomorphic for Dinosauriformes or even Ornithodira, but this is more ambiguous with our method. This is because these taxa all tend to be small-bodied and thus have relatively low estimated locomotor costs, close to the ecto/ endothermy boundary (or areas of overlapping costs between the two groupings). Endothermy, linked to rapid growth and high locomotor aerobic scope, may have presaged the evolution of advanced ventilatory anatomy and function, providing a critical locomotor advantage for dinosauromorphs, particularly in larger species.

\section{Materials and Methods}

\section{Dinosauriform Sample}

We used recent work linking locomotor anatomy to cost to determine the rate of energy expenditure during locomotion for fourteen species of extinct dinosauriform archosaurs, including Marasuchus and the giant flightless bird Dinornis (Table 1). We applied two different methods, one simple and one more complex, to do this.

Taxa were chosen for completeness, accessibility, and phylogenetic representation of the lineage from basal archosaurs to extant birds. All basal dinosauriforms were assumed to be bipedal although evidence for bipedalism is more ambiguous for some taxa, particularly Marasuchus and Plateosaurus. Our sampling is far from complete; inclusion of more basal dinosauromorphs/ dinosaurs, non-avian coelurosaurs, and basal birds could be interesting but we feel we have captured the basic diversity in body size and locomotor functional morphology with the chosen taxa. Our results suggest that additional taxa would show results similar to those in our sample with similar mass and locomotor anatomy. Adding more basal dinosauromorphs, for example, would add more values similar to those for Marasuchus. It is unclear how 
species with markedly different anatomy, such as large quadrupedal sauropods, would compare to the taxa in our sample.

\section{Estimating Locomotor Cost from Limb Length}

Our first, simpler method estimated the mass-specific locomotor cost of transport, COT $\left(\mathrm{mlO}_{2} \mathrm{~kg}^{-1} \mathrm{~m}^{-1}\right)$, using effective limb length (i.e., hip height); the distance from the hip joint to the ground while standing. In a recent comparison of locomotor cost in 28 terrestrial species, including 11 mammals, 8 birds, and 5 reptiles, effective limb length explained $98 \%$ of the variation in observed COT [39]. Moreover, once hip height was accounted for there was no independent effect of body mass on cost, indicating that effective limb length is the primary determinant of the welldocumented scaling of locomotor cost with body size [39]. Using reconstructed initial limb postures for the dinosaurs in this analysis (Figure 1; Table 1; [40]), we estimated COT from hip height as COT $\left(\mathrm{J} \mathrm{kg}^{-1} \mathrm{~m}^{-1}\right)=90.284(\text { Hip Height, cm })^{-0.77}$ following Pontzer [39], and converted to $\mathrm{mlO}_{2}$ assuming $1 \mathrm{mlO}_{2}=20.1$ Joules. This simple approach does not explicitly consider joint mechanics or muscle anatomy in estimating locomotor cost, effectively assuming that dinosauriforms followed the same scaling relationships for muscle fascicle length, $\mathrm{l}_{\text {fasc }}$, and joint effective mechanical advantage (EMA) as modern birds and mammals do $[29,39,41]$.

We multiplied COT by estimated body mass (Table 1) and walking or running speed in order to calculate the whole-body rate of oxygen consumption, $\mathrm{VO}_{2}\left(\mathrm{mlO}_{2} \mathrm{~s}^{-1}\right)$ during locomotion. Note that this approach gives the net rate of locomotor oxygen use, above the baseline rate of resting metabolism. Speeds were tailored to each species' body size using the Froude number [42], where $\mathrm{Fr}=\operatorname{speed}^{2}(\text { hip height } \cdot \mathrm{g})^{-1} \cdot \mathrm{VO}_{2}$ was calculated at a walk $(\mathrm{Fr}=0.25)$, a slow run $(\mathrm{Fr}=0.5)$, and a moderate run (Froude $=1.0$ ). Although running capacity in the largest theropods remains controversial, biomechanical solutions exist that allow slow to moderate-speed running (below Fr 5) [31,40,42-44] which we focus on here. Speeds and $\mathrm{VO}_{2}$ estimates are given in Table 1.

\section{Estimating Locomotor Cost from Active Muscle Volume}

The second, more complex, method we used to reconstruct COT and $\mathrm{VO}_{2}$ uses the volume of muscle activated to support and propel the body while walking and running to predict the cost of locomotion. Following previous experimental work [30,41,45-47] that indicates a strong link between the cost of generating muscular force to support body weight during the stance phase, we developed a model predicting COT $\left(\mathrm{mlO}_{2} \mathrm{~kg}^{-1} \mathrm{~m}^{-1}\right)$ from the mass-specific volume of muscle activated, $V_{\text {musc }}\left(\mathrm{cm}^{3} \mathrm{~kg}^{-1} \mathrm{~m}^{-1}\right)$, to support body weight during walking and running.

Using published data for 10 extant species (Table S1), the volume of muscle activated per unit of ground reaction force (GRF) was estimated as the mean fascicle length of the extensor muscles, $1_{\text {fasc }}$, divided by the joint's effective mechanical advantage or EMA [29,45-47]; the posture-dependent ratio of the antigravity muscle and GRF moment arms ( $\mathrm{r}$ and R, respectively) (Figure 1). Where available, EMA for extant taxa was calculated using forceplate-based measurements of R. For other extant species, EMA was calculated using a free-body diagram of a supportive hindlimb at mid-stance, including segmental gravitational (but not inertial; negligible at midstance) moments [48]. The poses input for these modeled taxa were based upon experimental data for running animals at mid-stance [48].

Where possible, modeled poses were updated with more recent kinematic data. For example, we used more accurate poses for quadrupedal (walking) alligators [49] as well as running ostriches
[50], but note that these updated poses did not change our results drastically when compared to prior reconstructions [48] (see Text $\mathrm{S} 1$ ). Also note that the alligator pose used in [48] was bipedal and not identical to the quadrupedal pose used here. Additionally, predicting total muscle volumes solely from hindlimb data for the extant quadrupeds simply assumes that the fore- and hindlimbs are acting with similar mechanical advantage, activating similar volumes of muscle to produce one Newton of GRF. This assumption is supported by force-plate studies in other quadrupeds (dogs [45] and quadrupedal chimpanzees [46]).

Using EMA and cadaver-based estimates of fascicle length, and assuming an isometric muscle stress of $200 \mathrm{kNm}^{-2}$ [46] (plausible variation of this parameter, $\pm 50 \%$, does not affect our ultimate results), we then estimated the volume of muscle needed to produce one Newton of GRF during locomotion. The volume per $1 \mathrm{~N}$ of GRF at each joint (hip, knee, and ankle) was summed, and then multiplied by $\mathrm{g} / \mathrm{step}$ length [41] to give the total mass-specific muscle volume, $\mathrm{V}_{\text {musc }}$, activated per meter travelled [30,44-47]. In our validation test of this model, $\mathrm{V}_{\text {musc }}$ predicted $98 \%$ of the variation in net (i.e., with resting costs removed) mass-specific COT $\left(\mathrm{r}^{2}=0.98, \mathrm{df}=9, \mathrm{p}<0.001\right.$; Figure Sla), indicating this method reliably predicts locomotor cost across a range of terrestrial vertebrates. This strong correlation remained even when the smallest species, Bobwhite quail, was removed $\left(\mathrm{r}^{2}=0.93\right.$, $\mathrm{df}=8, \mathrm{p}<0.001$, Figure $\mathrm{S} 1 \mathrm{~b})$. Notably, estimates of $\mathrm{V}_{\text {musc }}$ from both force-plate studies and from inverse dynamic models fit the $\mathrm{V}_{\text {musc }}$ /COT trendline equally well (Figure $\mathrm{S} 1$ ). Note that degrees of freedom reflect the number of species.

We then applied this validated model to the extinct dinosauriforms in our dataset in order to predict locomotor metabolic rate for these extinct bipeds. $V_{\text {musc }}$ for each dinosaur species was calculated as for extant species, using published reconstructions of EMA and $1_{\text {fasc }}[40,48]$; as in our extant sample, active muscle volume for the metatarsophalangeal joint in our dinosaur sample was excluded (see $[40,48]$ for discussion). Non-avian dinosaur step lengths were estimated from the ratio of step length to hip height in modern birds (step length $=1$. 1 hip height, ordinary least squares (OLS) regression: $\left.\mathrm{r}^{2}=0.87, \mathrm{n}=6, \mathrm{p}<0.01\right)$. We converted $\mathrm{V}_{\text {musc }}$ to COT using the OLS equation from our model, as COT $=0.0029$ $\mathrm{V}_{\text {musc }}+0.0598\left(\mathrm{r}^{2}=0.93, \mathrm{df}=8, \mathrm{p}<0.001\right.$; Figure $\left.\mathrm{S} 1 \mathrm{~B}\right)$. As with hip height based estimates of cost (above), we then multiplied COT by estimated body mass and speed to give the whole-body rate of oxygen consumption, $\mathrm{VO}_{2}\left(\mathrm{mlO}_{2} \mathrm{~s}^{-1}\right)$ during locomotion.

\section{Comparing $\mathrm{VO}_{2}$ for Dinosaurs to $\mathrm{VO}_{2} \mathrm{max}$ in Endotherms and Ectotherms}

$\mathrm{VO}_{2}$ for each dinosauriform was then compared to $\mathrm{VO}_{2}$ max for extant endotherms and ectotherms. $\mathrm{VO}_{2} \max$ data used in our comparative sample were from measurements reported explicitly as $\mathrm{VO}_{2}$ max, from the maximum reported aerobic power elicited during treadmill exercise studies, or, for three large varanid lizards, estimated as five times the field metabolic rate [51] measured in active, free-ranging animals. The use of maximum reported aerobic power from exercise studies will tend to underestimate true $\mathrm{VO}_{2}$ max. While this will have the effect of depressing the VO2max-Body Mass trendline (see below), this effect is very small for the ectotherm group in our sample, since most $(89 \%)$ of ectotherm measurements are explicit measurements of $\mathrm{VO}_{2}$ max. The effect on the endotherm trendline is likely somewhat larger; however, the critical comparison for our dinosauriform taxa is to the ectotherm range.

For comparison with net locomotor aerobic power $\left(\mathrm{mlO}_{2} / \mathrm{s}\right)$ predicted by our model, we subtracted resting metabolic rate (RMR, Watts), estimated from body mass $(\mathrm{kg})$ using published 
regressions (mammals [52]: $\mathrm{RMR}=3.40$ mass $^{0.75}$; birds [53]: $\mathrm{RMR}=3.79$ mass $^{0.72}$; reptiles $[54]: \quad \mathrm{RMR}=0.69 \mathrm{mass}^{0.82} ;$ all converted to $\mathrm{mlO}_{2}$ assuming $1 \mathrm{mlO}_{2}=20.1$ Joules, from these $\mathrm{VO}_{2}$ max measurements, and then plotted them against body mass. All measurements for ectotherms are from body temperatures of $30^{\circ}$ to $40^{\circ} \mathrm{C}$; when multiple measurements were reported, the measurement in the warmest environment (which typically is the highest $\mathrm{VO}_{2} \max$ value) was used (see Table S2). As reported previously [1], $\mathrm{VO}_{2}$ max in our sample of endotherms ( $\mathrm{n}=62$ birds and mammals) was an order of magnitude higher than for ectotherms ( $\mathrm{n}=37$ reptiles) of similar body mass (endotherm OLS trendline: $\mathrm{VO}_{2} \max =1.23 \mathrm{Mass}^{0.93}$, ectotherm: $\mathrm{VO}_{2} \max =$ 0.16 Mass $^{0.85}$, Figure 2).

Next, $\mathrm{VO}_{2} \max$ and body mass were $\log 10$ transformed, and compared using OLS in order to calculate the standard error of estimate (SEE) for this relationship. The 95\% confidence ranges for ectotherm and endotherm $\mathrm{VO}_{2}$ max were then calculated as \pm 2 SEE from their respective OLS trendlines. Due to the relatively large sample sizes for endotherms and ectotherms, removal of the largest and smallest taxa from this analysis had negligible effect on the confidence intervals, and did not affect the outcome of our dinosaur comparisons. Similarly, removal of ectothermic taxa for which $\mathrm{VO}_{2}$ max was estimated (Table S2) did not affect overall results in identifying dinosauriforms as endotherms.

To test this approach for distinguishing ectotherms and endotherms, we calculated $\mathrm{V}_{\text {musc }}$ and COT as above for three ectothermic and three endothermic species (Table S3). Our approach correctly placed moderate running $(\mathrm{Fr}=1.0)$ for two extant birds, and all locomotion for the extinct moa, in the endotherm range. Similarly, locomotor costs for the bipedal basilisk lizard, and for slow running in quadrupedal iguanas and alligators, were correctly placed in the ectotherm range (Figure S2).

The results of our sensitivity analyses for our models of dinosauriform anatomy, posture, and locomotor cost are outlined above, and are described in the Supporting Information (Text S1).

\section{Phylogenetic Analysis: When Did Endothermic-Level Locomotor Costs Evolve}

To test whether endothermy predated advanced lung structure in Saurischia, we mapped our quantitative data for our hip height and $\mathrm{V}_{\text {musc }}$-based estimates of locomotor cost onto a consensus phylogeny (Figure 3) of Archosauria, using Mesquite 2.6 [55] and coding the data as qualitative character states (see below). The phylogeny represents an informal "consensus" tree for Archosauria [56-68]. Alternative placements for taxa such as Dilophosaurus (i.e. moved to sister taxon with Coelophysis as $[62,68]$ rather than the initial position based on [64]) have minimal effects on the results; the positions of other taxa are generally uncontroversial. The data from Table 1 were used to code taxa into four character states of two characters: one from the conservative $\mathrm{VO}_{2}$ estimates of locomotor cost for slow walking, and one from the generally higher hip height estimates of locomotor cost. Character states were: (0) known ectotherms, (1) uncertain metabolic status (i.e. locomotor cost estimates within ectotherm 95\% CIs), (2) likely endotherms (i.e. locomotor cost estimates above ectotherm 95\% CIs) and (3) known endotherms.
Parsimony-based character optimization was then implemented in Mesquite to trace the evolution of these characters in Figure 3.

\section{Supporting Information}

Text S1 Explanation of methods and sensitivity analysis. Found at: doi:10.1371/journal.pone.0007783.s001 (0.05 MB DOC)

Table S1 Anatomical measurements, locomotor cost, step length, and active muscle volume for species used to validate the model.

Found at: doi:10.1371/journal.pone.0007783.s002 (0.05 MB DOG)

Table S2 Body mass, estimated resting metabolic rate (RMR), and maximum aerobic power $\left(\mathrm{VO}_{2 \max }\right)$ for extant species. RMR: estimated from mass; see text. Data type: $\mathrm{V}_{\mathrm{O} 2 \max }$, studies explicitly measuring maximum aerobic power; exercise, from highest reported aerobic power in a locomotion study; 5x FMR, fivetimes the reported field metabolic rate for this species. Temp.: environmental temperature for measurements of ectotherms.

Found at: doi:10.1371/journal.pone.0007783.s003 (0.18 MB DOC)

Table S3 Anatomical parameters, mass-specific active muscle volume $\left(\mathrm{V}_{\text {musc }}\right)$ and mass-specific cost of transport (COT) estimated for three endothermic and three ectothermic species. Found at: doi:10.1371/journal.pone.0007783.s004 (0.02 MB DOG)

Figure $\mathbf{S 1}$ Mass-specific active muscle volume $\left(\mathrm{V}_{\text {musc }}\right)$ versus cost of transport for the extant comparative sample. Black circles: $\mathrm{V}_{\text {musc }}$ data from force-plate trials, gray circles: $\mathrm{V}_{\text {musc }}$ modeled from free-body diagram analysis [45-47]; see Table S1.

Found at: doi:10.1371/journal.pone.0007783.s005 (0.17 MB DOC)

Figure S2 Cost of locomotion at Fr 0.25, 0.5, and 1.0 for three ectotherms (Basiliscus, Iguana, and Alligator, blue circles) and three endotherms (Eudromia, Gallus, and Dinornis, red circles). Symbols as in Figure 2a. Data in Table S3.

Found at: doi:10.1371/journal.pone.0007783.s006 (1.35 MB TIF)

\section{Acknowledgments}

We thank two anonymous reviewers, academic editor Andrew Farke, David Raichlen, Kevin Padian, Martin Bäker, Steve Gatesy, and the Structure and Motion Laboratory for constructive criticism that improved this study. Chelsea Kebodeaux assisted with manuscript preparation. We thank Heinrich Mallison for sharing data on Plateosaurus, and the University of California Museum of Paleontology (Berkeley, USA), American Museum of Natural History (New York, USA), and The Natural History Museum (London, UK) for access to specimens. We also thank Mark Davis, NOVA, and WGBH (Boston) for assisting with provision of the Microraptor sculpture by Jason Brougham.

\section{Author Contributions}

Conceived and designed the experiments: HP JH. Performed the experiments: HP JH. Analyzed the data: HP JH. Contributed reagents/ materials/analysis tools: VA. Wrote the paper: HP VA JH.

\section{References}

1. Bennett AF, Ruben JA (1986) The metabolic and thermoregulatory status of therapsids. In: Hotton N III, MacLean PD, Roth JJ, Roth EC, eds. The ecology of mammal-like reptiles, Smithsonian Institute Press: Washington DC. pp 207-218.

2. Bakker RT (1972) Anatomical and ecological evidence of endothermy in dinosaurs. Nature 238: 81-85.
3. Farlow JO, Dodson P, Chinsamy A (1995) Dinosaur biology. Ann Rev Ecol Syst 26: $445-471$.

4. Hillenius WJ, Ruben JA (2004) The evolution of endothermy in terrestrial vertebrates: Who? When? Why? Physiol Biochem Zool 77: 1019-1042.

5. Paul GS (1988) Predatory Dinosaurs of the World. Simon \& Schuster: New York. 
6. Schweitzer MH, Marshall CL (2001) A molecular model for the evolution of endothermy in the theropod-bird lineage. J Exp Zool (Mol Dev Evol) 291: 317-338.

7. O'Connor PM, Claessens LPAM (2005) Basic avian pulmonary design and flowthrough ventilation in non-avian theropod dinosaurs. Nature 436: 253-256.

8. Sereno PC, Martinez RN, Wilson JA, Varricchio DJ, Alcober OA, et al. (2008) Evidence for avian intrathoracic air sacs in a new predatory dinosaur from Argentina. PLoS ONE 3(9): e3303. doi:10.1371/journal.pone.0003303.

9. Wedel MJ (2008) Evidence for bird-like air sacs in saurischian dinosaurs. J Exp Zool 311A: 1-18.

10. Ruben JA, Hillenius WJ, Geist NR, Leitch A, Jones TD, et al. (1996) The metabolic status of some Late Cretaceous dinosaurs. Science 273: 1204-1207.

11. Ostrom JH (1980) The evidence for endothermy in dinosaurs. In: Thomas DK, Olson ECA, eds. A Cold Look at the Warm-Blooded Dinosaurs, Westview Press: Boulder CO. pp 15-54.

12. Seebacher F (2003) Dinosaur body temperatures: the occurrence of endothermy and ectothermy. Paleobiol 29: 105-22.

13. Paladino FV, O'Connor MP, Spotila JR (1990) Metabolism of leatherback turtles, gigantothermy, and thermoregulation of dinosaurs. Nature 344 : 858-860.

14. Chen P-J, Dong Z-M, Zhen S-N (1998) An exceptionally well-preserved theropod dinosaur from the Yixian Formation of China. Nature 391: 147-152.

15. Zheng X-T, You H-L, Xu X, Dong Z-M (2009) An Early Cretaceous heterodontosaurid dinosaur with filamentous integumentary structures. Nature 458: 333-336.

16. Chinsamy A, Chiappe LM, Dodson P (1995) Mesozoic avian bone microstructure: physiological implications. Paleobiol 21: 561-574.

17. Reid REH (1997) Dinosaurian physiology: the case for 'intermediate' dinosaurs. In: Farlow JO, Brett-Surman MK, eds. The complete dinosaur, Indiana Univ Press: Bloomington. pp 449-473.

18. de Ricqles AJ (1974) Evolution of endothermy: histological evidence. Evol Theor 1: $51-80$.

19. Padian K, Horner JR, de Ricqles A (2004) Growth in small dinosaurs and pterosaurs: the evolution of archosaurian growth strategies. J Vert Paleont 24: $555-571$.

20. Erickson GM, Curry Rogers K, Yerby SA (2001) Dinosaurian growth patterns and rapid avian growth rates. Nature 412: 429-433.

21. de Ricqles AJ, Padian K, Horner JR, Francillon-Viellot H (2000) Paleohistology of the bones of pterosaurs (Reptilia: Archosauria): anatomy, ontogeny and biochemical implications. Zool J Linn Soc 129: 349-385.

22. Padian K, de Ricqles A, Horner JR (2001) Dinosaurian growth rates and bird origins. Nature 412: 405-408.

23. Bennett AF, Ruben JA (1979) Endothermy and activity in vertebrates. Science 206: 649-654

24. Schmidt-Nielsen K (1997) Animal physiology: adaptation and environment (5th ed.). Cambridge Univ Press: Cambridge, UK. 205 p.

25. John-Adler HB, Garland T, Bennett AF (1986) Locomotor capacities, oxygen consumption, and the cost of locomotion of the shingle-back lizard (Trachydosaurus rugosus). Physiol Zool 59: 523-531.

26. Farmer CG (2000) Parental care: the key to understanding endothermy and other convergent features in birds and mammals. Am Nat 155: 326-334.

27. Farmer CG (2003) Reproduction: the adaptive significance of endothermy. Am Nat 162: 826-840.

28. Owerkowicz T, Farmer CG, Hicks JW, Brainerd EL (1999) Contribution of gular pumping to lung ventilation in monitor lizards. Science 284: 1661-1663.

29. Biewener AA (1989) Scaling body support in mammals: limb posture and muscle mechanics. Science 245: 45-48.

30. Pontzer H, Raichlen DA, Sockol MD (2009) The metabolic cost of walking in humans, chimpanzees, and early hominins. J Hum Evol 56: 43-54.

31. Gatesy SM, Bäker M, Hutchinson JR (2009) Constraint-based exclusion of limb poses for reconstructing dinosaur locomotion. J Vert Paleontol 29: 535-544.

32. Gleeson TT, Hancock TV (2002) Metabolic implications of a "run now, pay later" strategy in lizards: an analysis of post-exercise oxygen consumption. Comp Biochem Physiol A 133: 259-267.

33. Sereno PC (1991) Basal archosaurs: phylogenetic relationships and functional implications. J Vert Paleontol Spec Mem 2: 1-53.

34. Haubold H (1999) Tracks of the Dinosauromorpha from the lower Triassic. Zbl Geol Palaont, Teil I, Heft 7-8: 783-95.

35. Spotilla JR, Lommen PW, Bakken GS, Gates DM (1973) A mathematical model for body temperature of large reptiles: Implications for dinosaur endothermy. Am Nat 107: 391-404.

36. Gillooly JF, Allen AP, Charnov EL (2006) Dinosaur fossils predict body temperatures. Pub Libr Sci Biol 4: 1467-1469.

37. Rubenson J, Heliams DB, Maloney SK, Withers PC, Lloyd DG, et al. (2007) Reappraisal of the comparative cost of locomotion using gait-specific allometric analyses. J Exp Biol 210: 3513-3524.
38. Claessens LPAM, O'Connor PM, Unwin DM (2009) Respiratory evolution facilitated the origin of pterosaur flight and aerial gigantism. PLoS ONE 4(2): e4497. doi:10.1371/journal.pone.0004497.

39. Pontzer, $H$ (2007) Effective limb length and the scaling of locomotor cost in terrestrial animals. J Exp Biol 210: 1752-1761.

40. Hutchinson JR (2004a) Biomechanical modeling and sensitivity analysis of bipedal running ability. II. Extinct taxa. J Morphol 262: 441-461.

41. Kram R, Taylor CR (1990) Energetics of running: a new perspective. Nature 346: 265-267.

42. Alexander RMcN, Jayes AS (1983) A dynamic similarity hypothesis for the gaits of quadrupedal mammals. J Zool 201: 135-152.

43. Sellers WI, Manning PL (2007) Estimating dinosaur maximum running speeds using evolutionary robotics. Proc Roy Soc Lond B 274: 2711-2716.

44. Hutchinson JR, Allen V (2009) The evolutionary continuum of limb function from early theropods to birds. Naturwiss 96: 423-448.

45. Roberts TJ, Chen MS, Taylor CR (1998) Energetics of bipedal running: II. Limb design and running mechanics. J Exp Biol 201: 2753-2762.

46. Sockol MD, Raichlen DA, Pontzer H (2007) Chimpanzee locomotor energetics and the origin of human bipedalism. Proc Nat Acad Sci USA 30: 12265-12269.

47. Biewener AA, Farley CT, Roberts TJ, Temaner M (2004) Muscle mechanical advantage of human walking and running: implications for energy cost. J Appl Physiol 97: 2266-2274.

48. Hutchinson JR (2004b) Biomechanical modeling and sensitivity analysis of bipedal running ability. I. Extant taxa. J Morphol 262: 421-440.

49. Gatesy SM (1991) Hind limb movements of the American alligator (Alligator mississippiensis) and postural grades. J Zool 224: 577-588.

50. Rubenson J, Lloyd DG, Besier TF, Heliams DB, Fournier PA (2007) Running in ostriches (Struthio camelus): three-dimensional joint axes alignment and joint kinematics. J Exp Biol 210: 2548-2562.

51. Nagy KA, Girard IA, Brown TK (1999) Energetics of free-ranging mammals, reptiles, and birds. Ann Rev Nutr 19: 247-277.

52. Kleiber M (1961) The fire of life. Wiley: New York.

53. Lasiewski RC, Dawson WR (1967) A re-examination of the relationship between standard metabolic rate and body weight in birds. Condor 69: 13-23.

54. Bennett AF, Dawson, WR (1976) Metabolism. In: Gans C, Dawson WR, eds. Biology of the Reptilia, volume 5, Academic Press: New York. pp 127-223.

55. Maddison WP, Maddison DR (2009) Mesquite: a modular system for evolutionary analysis. Version 2.6: http://mesquiteproject.org.

56. Gauthier J, Kluge AG, Rowe T (1988) Amniote phylogeny and the importance of fossils. Cladistics 4: 105-209.

57. Novas FE (1996) Dinosaur monophyly. J Vert Paleontol 16: 723-741.

58. Sereno PC (1999) The evolution of dinosaurs. Science 284: 2137-2147.

59. Cooper A, Lalueza-Fox C, Anderson S, Rambaut A, Austin J, et al. (2001) Complete mitochondrial genome sequences of two extinct moas clarify ratite evolution. Nature 409: 704-707.

60. Mayr G, Clarke J (2003) The deep divergences of neornithine birds: a phylogenetic analysis of morphological characters. Cladistics 19: 527-553.

61. Dyke GJ, van Tuinen M (2004) The evolutionary radiation of modern birds (Neornithes): reconciling molecules, morphology and the fossil record. Zool J Lin Soc 141: 153-177.

62. Carrano MT, Hutchinson JR, Sampson SD (2005) New information on Segisaurus halli, a small theropod dinosaur from the Early Jurassic of Arizona, J Vert Paleontol 25: 835-849.

63. Langer MC, Benton MJ (2006) Early dinosaurs: A phylogenetic study. J Syst Palaeontol 4: 309-358.

64. Smith ND, Makovicky PJ, Hammer WR, Currie PJ (2007) Osteology of Cryolophosaurus ellioti (Dinosauria: Theropoda) from the Early Jurassic of Antarctica and implications for early theropod evolution. Zool J Linn Soc 151: $377-421$.

65. Turner AH, Pol D, Clarke JA, Erickson GM, Norell MA (2007) A basal dromaeosaurid and size evolution preceding avian flight. Science 317: 1378-1381.

66. Butler RJ, Upchurch P, Norman DB (2008) The phylogeny of the ornithischian dinosaurs. J Syst Palaeontol 6: 1-40.

67. Brusatte S, Sereno PC (2008) Phylogeny of Allosauroidea (Dinosauria: Theropoda): comparative analysis and resolution. J Syst Palaeontol 6: 155-182.

68. Carrano MT, Sampson SD (2008) The phylogeny of Ceratosauria (Dinosauria: Theropoda), J Syst Palaeontol 6: 183-236.

69. Hutchinson JR, Ng-Thow-Hing V, Anderson FC (2007) A 3D interactive method for estimating body segmental parameters in animals: application to the turning and running performance of Tyrannosaurus rex. J Theor Biol 246: 660-680.

70. Gunga H-C, Suthau T, Bellman H, Friedrich A, Schwanebeck T, et al. (2007) Body mass estimations for Plateosaurus engelhardti using laser scanning and 3D reconstruction methods. Naturwissenschaften 94: 623-630. 